\title{
Phase la study of the indoleamine 2,3- dioxygenase 1 (IDO1) inhibitor navoximod (GDC-0919) in patients with recurrent advanced solid tumors
}

Asha Nayak-Kapoor ${ }^{1}$, Zhonglin Hao ${ }^{1}$, Ramses Sadek ${ }^{1}$ Robin Dobbins ${ }^{1}$, Lisa Marshall ${ }^{1}$, Nicholas N. Vahanian², W. Jay Ramsey ${ }^{2}$, Eugene Kennedy ${ }^{2}$, Mario R. Mautino², Charles J. Link², Ray S. Lin³, Stephanie Royer-Joo ${ }^{3}$, Xiaorong Liang ${ }^{3}$, Laurent Salphati ${ }^{3}$, Kari M. Morrissey ${ }^{3}$, Sami Mahrus $^{3}$, Bruce McCall ${ }^{3}$, Andrea Pirzkall ${ }^{3}$, David H. Munn ${ }^{1}$, John E. Janik ${ }^{1}$ and Samir N. Khleif ${ }^{1,4^{*}}$

\section{Abstract}

Background: Indoleamine-2,3-dioxygenase 1 (IDO1) catalyzes the oxidation of tryptophan into kynurenine and is partially responsible for acquired immune tolerance associated with cancer. The IDO1 small molecule inhibitor navoximod (GDC-0919, NLG-919) is active as a combination therapy in multiple tumor models.

Methods: This open-label Phase la study assessed safety, pharmacokinetics (PK), pharmacodynamics (PD), and preliminary anti-tumor activity of navoximod in patients with recurrent/advanced solid tumors, administered as $50-800 \mathrm{mg}$ BID on a 21/28 day and at $600 \mathrm{mg}$ on a 28/28 day schedule. Plasma kynurenine and tryptophan were longitudinally evaluated and tumor assessments were performed.

Results: Patients ( $n=22$ ) received a median of 3 cycles of navoximod. No maximum tolerated dose was reached. One dose-limiting toxicity of Grade 4 lower gastrointestinal hemorrhage was reported. Adverse events (AEs) regardless of causality in $\geq 20 \%$ of patients included fatigue (59\%), cough, decreased appetite, and pruritus (41\% each), nausea (36\%), and vomiting (27\%). Grade $\geq 3$ AEs occurred in 14/22 patients (64\%), and were related to navoximod in two patients (9\%). Navoximod was rapidly absorbed $\left(T_{\max } \sim 1 \mathrm{~h}\right)$ and exhibited dose-proportional increases in exposure, with a half-life $\left(\mathrm{t}_{1 / 2} \sim 11 \mathrm{~h}\right)$ supportive of BID dosing. Navoximod transiently decreased plasma kynurenine from baseline levels with kinetics consistent with its half-life. Of efficacy-evaluable patients, 8 (36\%) had stable disease and 10 (46\%) had progressive disease.

Conclusions: Navoximod was well-tolerated at doses up to $800 \mathrm{mg}$ BID decreasing plasma kynurenine levels consistent with its half-life. Stable disease responses were observed.

Trial registration: ClinicalTrials.gov identifier: NCT02048709.

Keywords: Phase I, IDO1, Navoximod, Kynurenine, Tryptophan

\footnotetext{
* Correspondence: snk48@georgetown.edu

${ }^{1}$ Georgia Cancer Center at Augusta University, Augusta, GA, USA

${ }^{4}$ Present Address: Lombardi Comprehensive Cancer Center, Georgetown

University School of Medicine, 3900 Reservoir Rd NW, Washington, DC 20007,

USA

Full list of author information is available at the end of the article
}

C The Author(s). 2018 Open Access This article is distributed under the terms of the Creative Commons Attribution 4.0 International License (http://creativecommons.org/licenses/by/4.0/), which permits unrestricted use, distribution, and reproduction in any medium, provided you give appropriate credit to the original author(s) and the source, provide a link to the Creative Commons license, and indicate if changes were made. The Creative Commons Public Domain Dedication waiver (http://creativecommons.org/publicdomain/zero/1.0/) applies to the data made available in this article, unless otherwise stated. 


\section{Background}

Indoleamine 2,3-dioxygenase 1 (IDO1) is a cytosolic enzyme that catalyzes the first and rate-limiting step in the oxidation of L-tryptophan (Trp) into kynurenine (Kyn) [1]. IDO1 is constitutively expressed in many tissues where it regulates local inflammation and moderates response to foreign or uncommon non-pathological antigens. The IDO1 pathway contributes to local control of inflammation and participates in acquired immune peripheral tolerance to limit inflammation and prevent normal tissue injury.

In cancer cells, IDO1 mediates an acquired immunosuppression leading to local and systemic immune tolerance towards the tumor by helping to evade immune surveillance [2]. IDO1 has at least two methods for inducing immune suppression in T cells. First, depletion of Trp in the local tumor microenvironment activates a starvation response in $\mathrm{T}$ cells that impairs their function. Second, increase in levels of Kyn, an endogenous ligand for the aryl hydrocarbon receptor, suppresses effector $\mathrm{T}$ cells and hyperactivates Tregs. Together, these effects lead to decreased inflammation and immune responsivity $[3,4]$. Inhibition of IDO1 activity reverts these effects, while also modulating the function of dendritic cells and skewing antigen presentation away from a tolerogenic phenotype.

IDO1 is expressed by many tumors including malignant melanoma [5, 6], pancreatic cancer [7], ovarian cancer $[8,9]$, acute myelogenous leukemia [10, 11], colorectal cancer [12, 13], prostate cancer [14], and endometrial cancer $[15,16]$. Increased tumor expression of IDO1 has been associated with significantly worse clinical outcomes [1]. Recently, the IDO inhibitor epacadostat (INCB024360) showed reductions in plasma Kyn levels in an ex vivo assay in patients with advanced solid malignancies [17]. Combination studies examining IDO1 inhibitors given with checkpoint blockade via programmed cell death protein 1 (PD-1) or programmed death-ligand 1 (PD-L1) inhibition appears more promising in light of encouraging response rates and durability of responses [18-21], which is now being evaluated in Phase III clinical trials.

Navoximod (GDC-0919; previously NLG919) is an investigational small molecule inhibitor of IDO1 that was developed to treat the immune tolerance associated with cancer. Navoximod shows a potency $\left(\mathrm{EC}_{50}\right)$ of $70 \mathrm{nM}$ in cellular activity assays and $90 \mathrm{nM}$ in human $\mathrm{T}$ cell-proliferation MLR assays [22]. In preclinical models, combination treatment of navoximod with chemotherapy, radiotherapy, or vaccines leads to improved antitumor response [23]. Treatment with navoximod and vaccination in B16F10 tumor-bearing mice increased the $\mathrm{T}$ cell response, leading to improved anti-tumor efficacy [22]. In preclinical combination studies with anti-PD-L1 and anti-OX40, inhibition of IDO1 showed greater effect in activating intratumoral $\mathrm{CD}^{+} \mathrm{T}$ cells and inhibiting tumor growth than either treatment alone [22, 24-26].

These data support the investigation of navoximod as a cancer immunotherapeutic agent. The primary objectives of this study were to evaluate the safety and tolerability of single-agent navoximod and to determine the maximum tolerated dose (MTD) in patients with recurrent advanced solid tumors. We also sought to characterize the pharmacokinetic (PK) properties of navoximod after single and repeat doses, and identify the single-agent recommended Phase II dose and schedule. Other objectives included assessment of pharmacodynamic (PD) modulation of plasma Kyn and Trp by navoximod, and an evaluation of response rates and duration of responses.

\section{Methods \\ Study design}

This was a single-arm, single-center, non-randomized Phase I open-label, dose-ranging study of navoximod (supplied by NewLink Genetics and later Genentech, Inc.) in patients with recurrent, advanced solid tumors. All patients were enrolled at the Georgia Cancer Center at Augusta University, Augusta, GA.

Based on validated preclinical models to establish the starting dose of navoximod in line with standard Phase I oncology clinical trials, and predicted half-life, the navoximod starting dose was defined as $50 \mathrm{mg}$ twice daily (BID), and after that dose was demonstrated to be safe, navoximod was escalated in a modified $3+3$ design at doses of 100, 200, 400, 600, and $800 \mathrm{mg}$ BID for 21 days, followed by 7 days without dose administration (21/28 day schedule). Navoximod was administered every $12 \mathrm{~h}$ on an empty stomach (no food or drink other than water for at least $2 \mathrm{~h}$ prior to dose and at least $1 \mathrm{~h}$ after dose). Having demonstrated good tolerability at the $21 / 28$ schedule, a continuous dosing cohort of $600 \mathrm{mg}$ BID for 28 days was added (28/28-day schedule). Figure 1 shows the study design, dose levels, timepoints for PK/ $\mathrm{PD}$, tumor assessments, and number of patients entered in each cohort. MTD was defined as the highest dose at which 2 out of 6 treated patients experienced Dose limiting Toxicity (DLT) in the first cycle. DLTs were defined as any clinically significant non-hematologic toxicity of Grade 3 or greater that occurred during the first cycle of 14 days (excluding Grade 3 nausea, vomiting, diarrhea managed with optimal medication) not related to underlying malignancy; an immune related adverse event (AE) that lasted more than 28 days (an $\mathrm{AE}$ associated with exposure to the study drug and that was consistent with an immune phenomenon); or hematological toxicity (Grade 4 neutropenia, Grade 3 or greater febrile 


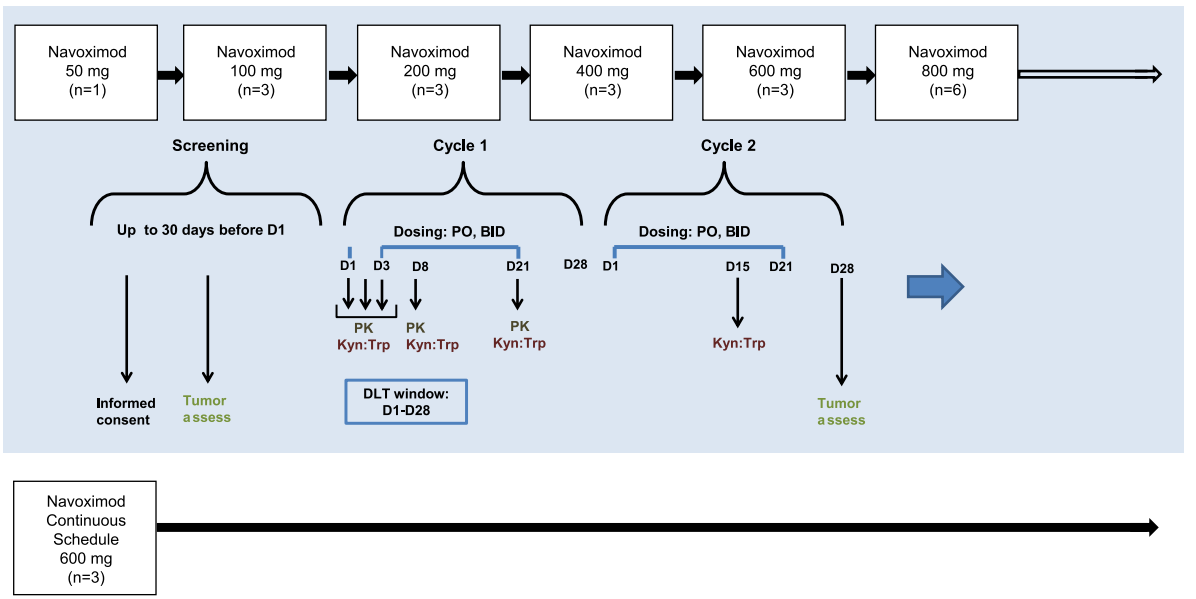

Fig. 1 Study design for ascending (BID) and continuous schedules

neutropenia, or Grade 4 thrombocytopenia that persisted more than 5 days despite optimal management).

\section{Patients}

Eligible patients were age $\geq 18$ years with histologically confirmed solid tumors that were refractory to standard therapies or for which no approved or curative therapy was available, had Eastern Cooperative Oncology group (ECOG) performance status of $0-1$, adequate hematologic and end organ function, and evaluable or measurable disease per RECIST v1.1. Patients were excluded if there was a history of autoimmune disease, prior treatment with any anti-cancer therapy, cytokines or toll-like receptors within 5 drug half-lives, antibodies directed at PD-1, PD-L1 or CTLA4, or other IDO inhibitors, prior malignancy other than non-melanoma skin cancer or carcinoma in situ of the cervix, infection with HIV, Hepatitis B or C, concomitant immunotherapy, untreated brain metastases, or current treatment with drugs associated with Torsades de Pointes, which could not be safely discontinued.

\section{Safety assessments}

Safety assessments consisted of per-visit monitoring and recording AEs, including serious and nonserious AEs of special interest (cases of potential drug induced liver injury that included an elevated ALT or AST in combination with either an elevated bilirubin or clinical jaundice, as defined by Hy's law, and any DLT). Protocol-specified laboratory assessments, were also performed. AEs were monitored and graded for severity using the National Cancer Institute Common Terminology Criteria for Adverse Events, version 4.0.

\section{Pharmacokinetic assessments}

Frequent blood samples were taken for navoximod PK evaluations after single (Cycle 1, Day 1-3 [0-48 h]) and multiple twice-daily doses (Cycle 1, Day 21 [0-12 h]). Plasma concentrations of navoximod were determined using a validated liquid chromatographic-tandem mass spectrometry (LC/MS-MS) method with a lower limit of quantitation of $1 \mathrm{ng} / \mathrm{mL}$. The LC/MS/MS method employed $\left[{ }^{13} \mathrm{C},{ }^{15} \mathrm{~N}_{2}\right]$-navoximod as the internal standard. Samples were processed using protein precipitation extraction procedures. Chromatography of navoximod was achieved with a Waters Atlantis T3 $(50 \times 4.6 \mathrm{~mm}, 5 \mu \mathrm{m})$ column. A Sciex API 4000 with an electrospray source in the positive ion multiple-reaction monitoring mode was used for detection of navoximod in human plasma. The dynamic range of the assay for navoximod was $1-1000 \mathrm{ng} / \mathrm{mL}$. The intra-run and inter-run precision was within $6.1 \%$ and accuracy was within $\pm 9.6 \%$ of the nominal concentration values. Navoximod was found to be stable in human plasma over 5 freeze-thaw cycles, at least for 110 days at $-10{ }^{\circ} \mathrm{C}$ to $-30{ }^{\circ} \mathrm{C}$ and $-60{ }^{\circ} \mathrm{C}$ to $-80{ }^{\circ} \mathrm{C}$, and for $24 \mathrm{~h}$ at room temperature. PK parameters were estimated using noncompartmental analysis (Phoenix WinNonlin 6.4; Certara, Princeton, NJ).

\section{Tumor response assessments}

Objective tumor assessments by the investigators, including an assigned radiologist and confirmed by the clinical investigators, were conducted using $\mathrm{CT}$ or MRI studies obtained at screening, at Cycle 4, and approximately every 4th cycle thereafter, according to RECIST v1.1 and immune related response criteria (irRC). Endpoints included complete or partial response and stable disease, which were confirmed by tumor imaging. 


\section{Plasma biomarker assessments}

Blood was collected to monitor changes in plasma Kyn and Trp levels as peripheral markers of IDO1 activity modulation. Samples were collected at the same schedule as PK assessments, with another sample drawn at the 1 week scheduled clinic visit (Day 8). After collection, blood samples were centrifuged at 2000xg for $15 \mathrm{~min}$ in a refrigerated centrifuge at $2-8^{\circ} \mathrm{C}$ to harvest the plasma and plasma samples were stored at $-70^{\circ} \mathrm{C}$ until analysis. Validated LC/MS-MS assays were used to measure the concentration of Kyn and Trp in plasma samples, with lower limits of quantitation of $25 \mathrm{ng} / \mathrm{mL}$ and $500 \mathrm{ng} / \mathrm{mL}$, respectively. The intra-run and interrun precision was within $4.7 \%$ and accuracy was within $\pm 4.5 \%$ of the nominal concentration values for both analytes. Samples were analyzed at Covance Laboratories, Madison, WI.

\section{Statistical analyses}

No formal hypotheses were tested in this study, and all analyses were descriptive and exploratory. Design considerations were not made with regard to explicit power and type I error, but to obtain preliminary safety, activity, pharmacokinetic, and pharmacodynamic information. For the safety and activity analyses, all patients who received $\geq 1$ dose of navoximod were included. The number of patients enrolled at each dose level and the number of dose cohorts were determined by the safety profile observed during the course of the study.

\section{Results}

The study was initiated in April 2014, enrolled 22 patients in 7 Cohorts (navoximod 50-800 mg BID on two treatment schedules) and was terminated early by the Sponsor in December 2016. The study was closed before completing planned enrollment as a result of increasing challenges to identifying suitable patients for the study.

\section{Patient characteristics}

All the data presented herein are based on a data cut of Nov 16, 2016. A total of 22 patients were enrolled and received $\geq 1$ dose of navoximod. The baseline characteristics of the patient population are shown in Table 1. The median age was 61 years with more males (68\%)

Table 1 Patient baseline and disease characteristics

\begin{tabular}{|c|c|c|c|c|c|c|c|c|}
\hline \multirow[t]{2}{*}{ Variable } & \multicolumn{6}{|c|}{ Navoximod $21 / 28$ days BID } & \multirow{2}{*}{$\begin{array}{l}\text { Navoximod 28/ } \\
28 \text { days BID } \\
600 \mathrm{mg} \\
(n=3)\end{array}$} & \multirow{2}{*}{$\begin{array}{l}\text { All patients } \\
(n=22)\end{array}$} \\
\hline & $\begin{array}{l}50 \mathrm{mg} \\
(n=1)\end{array}$ & $\begin{array}{l}100 \mathrm{mg} \\
(n=3)\end{array}$ & $\begin{array}{l}200 \mathrm{mg} \\
(n=3)\end{array}$ & $\begin{array}{l}400 \mathrm{mg} \\
(n=3)\end{array}$ & $\begin{array}{l}600 \mathrm{mg} \\
(n=3)\end{array}$ & $\begin{array}{l}800 \mathrm{mg} \\
(n=6)\end{array}$ & & \\
\hline Age (yr), median (range) & $65(65-65)$ & $58(50-82)$ & $63(32-75)$ & $54(41-69)$ & $58(27-59)$ & $69(38-70)$ & $67(43-72)$ & $61(27-82)$ \\
\hline \multicolumn{9}{|l|}{ Sex } \\
\hline Female & $1(100 \%)$ & - & $3(100 \%)$ & $3(100 \%)$ & $3(100 \%)$ & $3(50 \%)$ & $2(67 \%)$ & $15(68 \%)$ \\
\hline Male & - & $3(100 \%)$ & - & - & - & $3(50 \%)$ & $1(33 \%)$ & $7(32 \%)$ \\
\hline \multicolumn{9}{|l|}{ ECOG performance status } \\
\hline 0 & $1(100 \%)$ & $1(33 \%)$ & $3(100 \%)$ & - & $1(33 \%)$ & $1(17 \%)$ & $2(67 \%)$ & $9(41 \%)$ \\
\hline 1 & - & $2(67 \%)$ & - & $3(100 \%)$ & $2(67 \%)$ & $5(83 \%)$ & $1(33 \%)$ & $13(59 \%)$ \\
\hline \multicolumn{9}{|l|}{ Most common tumor types } \\
\hline Colorectal & - & - & - & $2(67 \%)$ & - & $4(67 \%)$ & - & $6(27 \%)$ \\
\hline Head and neck & - & - & $1(33 \%)$ & $1(33 \%)$ & - & $1(17 \%)$ & - & $3(14 \%)$ \\
\hline Leiomyosarcoma & - & $1(33 \%)$ & & - & - & - & $1(33 \%)$ & $2(9 \%)$ \\
\hline Lung & - & $1(33 \%)$ & $1(33 \%)$ & - & - & - & - & $2(9 \%)$ \\
\hline Pancreas & - & - & $1(33 \%)$ & - & $1(33 \%)$ & - & - & $2(9 \%)$ \\
\hline Renal & - & - & - & - & $1(33 \%)$ & $1(17 \%)$ & - & $2(9 \%)$ \\
\hline Bladder & $1(100 \%)$ & - & - & - & - & - & - & $1(5 \%)$ \\
\hline Breast & - & - & - & - & - & - & $1(33 \%)$ & $1(5 \%)$ \\
\hline Cholangiocarcinoma & - & $1(33 \%)$ & - & - & - & - & - & $1(5 \%)$ \\
\hline Mesothelioma & - & - & - & - & - & - & 1 (33\%) & $1(5 \%)$ \\
\hline Testicular & - & - & - & - & $1(33 \%)$ & - & - & $1(5 \%)$ \\
\hline $\begin{array}{l}\text { Number of prior systemic } \\
\text { therapies, median (range) }\end{array}$ & $5(5-5)$ & $4(1-5)$ & $3(1-3)$ & $4(3-4)$ & $3(2-9)$ & $3.5(2-6)$ & & \\
\hline
\end{tabular}


enrolled than females. The majority of patients were white (73\%). Thirteen patients (59\%) had an ECOG score of 1 at baseline. Colorectal cancer (27\%) made up the highest proportion of malignancies, followed by head and neck cancer (14\%). All patients had received $\geq 1$ prior systemic therapy with a median of 3 (range 1-9), and 18 patients received $\geq 1$ prior course of radiation therapy.

\section{Dose escalation of navoximod}

Across all dose cohorts of patients (50-800 mg BID), the median number of 28-day cycles of navoximod received per patient was 3 (range 1-20) and patients remained on study treatment a median of 75 days (range 2-552 days).

\section{Safety, tolerability, and adverse events}

All patients experienced $\geq 1 \mathrm{AE}$ during the study regardless of attribution to navoximod (Table 2). The MTD was not reached. A DLT was reported in 1 patient (69 year old male) in Cohort 6 (800 mg BID, 21/28 days schedule) with metastatic renal cell carcinoma. This patient experienced Grade 1 diarrhea with dark stool at Cycle 1, Day 14, Grade 3 hypotension that worsened to Grade 4, and Grade 4 lower gastrointestinal hemorrhage, treated with blood transfusion and vasopressors, and was assessed as possibly related to navoximod. However, even though the relationship to the study treatment could not be ruled out, this patient exhibited widespread peritoneal and GI serosal metastasis on baseline CT scan that could explain the symptoms.

Grade $\geq 3$ AEs regardless of attribution were reported in $14(64 \%)$ patients (Table 3) and Grade $\geq 3 \mathrm{AE}$ related to navoximod were reported in two patients (9\%): Grade 4 lower gastrointestinal hemorrhage described above, and Grade 3 diverticulitis on Day 155 in a patient with leiomyosarcoma treated at $600 \mathrm{mg}$ BID on the continuous dosing schedule.

Review of electrocardiograph data collected at baseline, Cycle 1, Day 1, and Cycle 1, Day 8 did not suggest a risk of QT prolongation with navoximod. Liver function test abnormalities (increased aspartate aminotransferase and alanine aminotransferase) were observed in a total of four patients (18\%).

Two patients required dose modifications: 1 dose interruption in the $100 \mathrm{mg}$ BID cohort (Grade 1 tachycardia, dyspnea, and nausea), and another dose interruption/reduction from 800 to $600 \mathrm{mg}$ BID due to Grade 2 AST/ALT and Grade 2 maculopapular rash. No AEs requiring withdrawal of study drug were reported. Reasons for discontinuation from study treatment included disease progression (20 patients), physician's decision (1 patient) and patient withdrawal (1 patient). Three patients died during the 30-day safety follow-up due to disease progression.

\section{Pharmacokinetic analysis}

Under fasting conditions, navoximod was rapidly absorbed $\left(\mathrm{T}_{\max } \sim 1 \mathrm{~h}\right)$ and demonstrated linear and dose proportional increases in exposure, with an average halflife across all dose levels of $\sim 12 \mathrm{~h}$, which is supportive of BID dosing (Fig. 2). The mean accumulation index (MD $\mathrm{AUC}_{0-12} / \mathrm{SD} \mathrm{AUC}_{0-12}$ ) was 1.7, consistent with its half-life and a BID dosing interval.

\section{Clinical activity}

Time on study treatment, reasons for treatment discontinuation, and best response are shown in Fig. 3. No post-baseline tumor assessments were available for four patients who discontinued due to clinical progression prior to the initial tumor assessment. Based on RECIST v1.1 there were no objective responses, and the best response was limited to stable disease (SD) in 8/22 (36\%) patients who were distributed amongst all dose cohorts. Ten patients (45\%) had progressive disease.

Based on irRC there were no objective responses, and the rate of SD was $12 / 22(68 \%)$ based on tumor assessments in target lesions only (irRC requires confirmation of PD 4 weeks after initial assessment). One patient only had non-target lesions at baseline and could not be assessed via irRC.

One patient with a diagnosis of leiomyosarcoma of the colon remained on study treatment for over 13 months with best response of SD. This patient was enrolled with presumed tumor progression after prior chemotherapy, but upon re-examination of baseline CT scans tumor progression prior to study entry was not confirmed.

The lack of objective responses is consistent with preclinical data which indicates that IDO inhibition is only effective in the context of chemotherapy, vaccination, radiation and/or checkpoint inhibition. Moreover, these results parallel those observed for epacadostat as single agent, which reported no objective responses and 35\% SD response by RECIST [17].

\section{Pharmacodynamics}

At higher doses including 400, 600, and $800 \mathrm{mg}$ BID, navoximod decreased plasma Kyn from baseline levels by $25-30 \%, 2-4 \mathrm{~h}$ after dosing, with kinetics that were consistent with the half-life of the drug (Fig. 4a). In the context of 95\% confidence intervals (colored in gray), the mean change from baseline was statistically significant at the 2, 4, and $6 \mathrm{~h}$ post-dose timepoints in the $400 \mathrm{mg}$ BID cohort, at the 1,2 , and 4 h post-dose timepoints in the $600 \mathrm{mg}$ BID cohort, and at all timepoints including $1 \mathrm{~h}$ post-dose and beyond in the $800 \mathrm{mg}$ BID cohort. At $800 \mathrm{mg}$ BID, similar maximal decreases in Kyn were observed after multiple doses of navoximod (Fig. 4b). No significant modulation of plasma Trp levels was observed on days 1 or 21 (results not shown). 


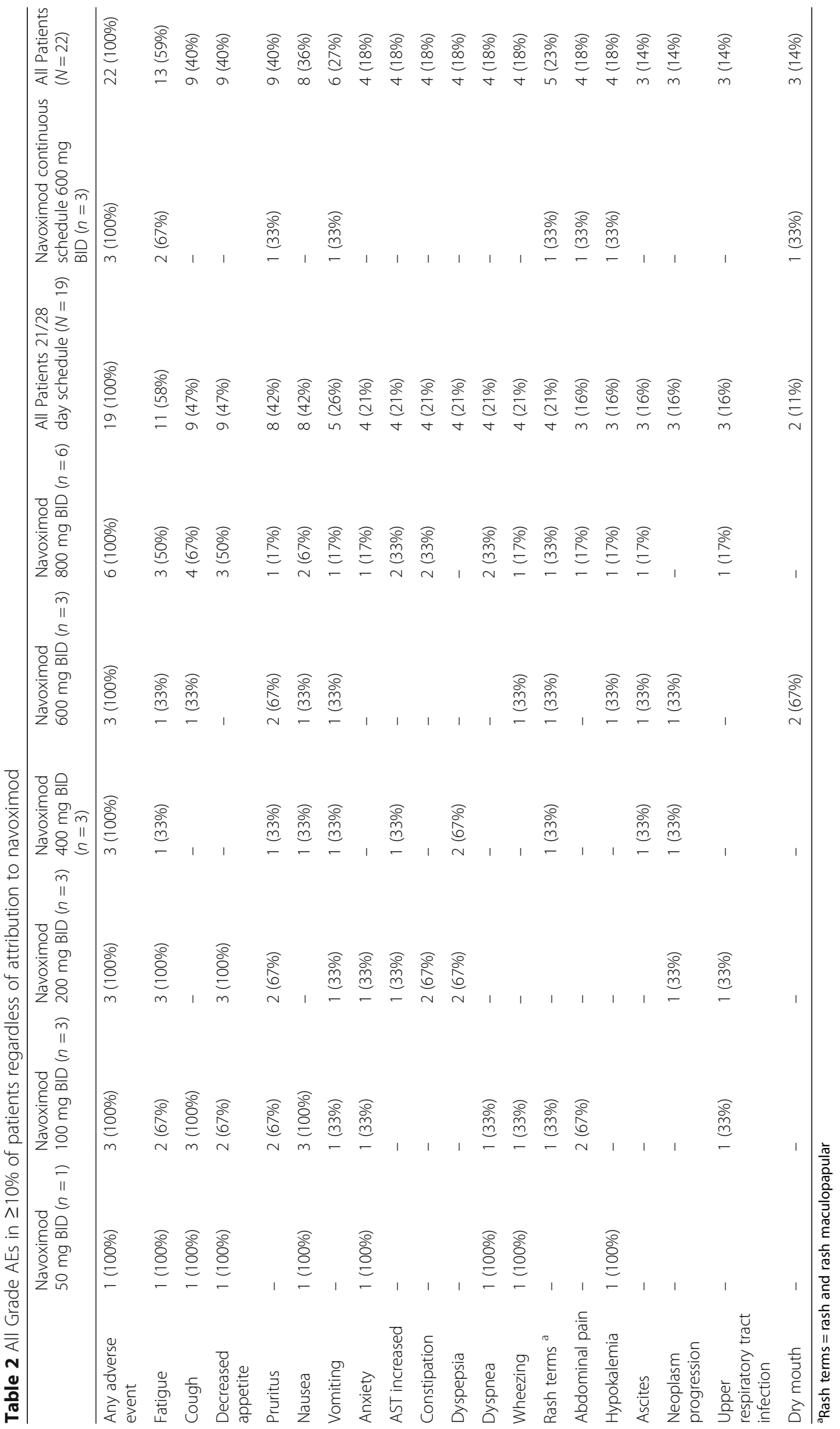




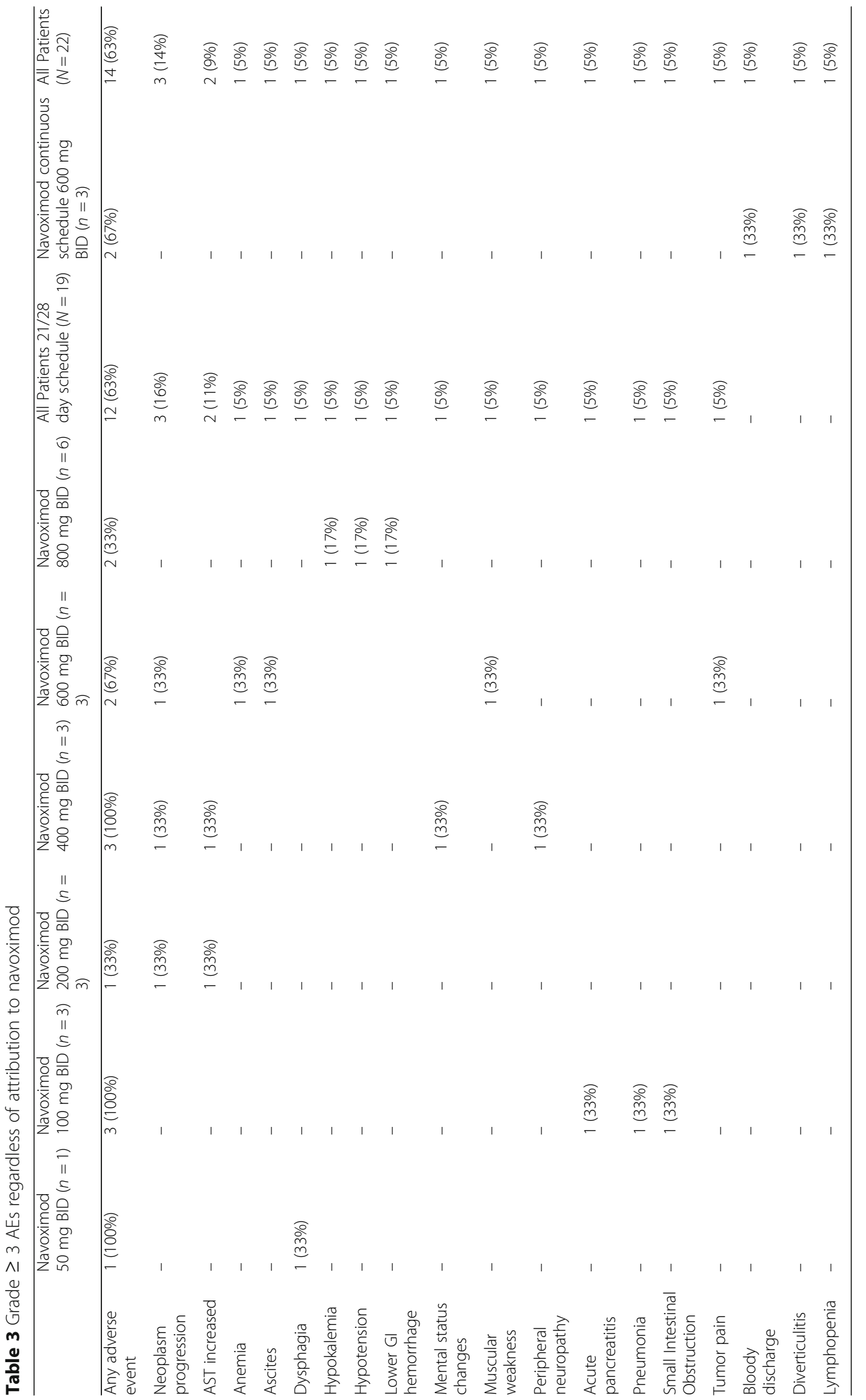




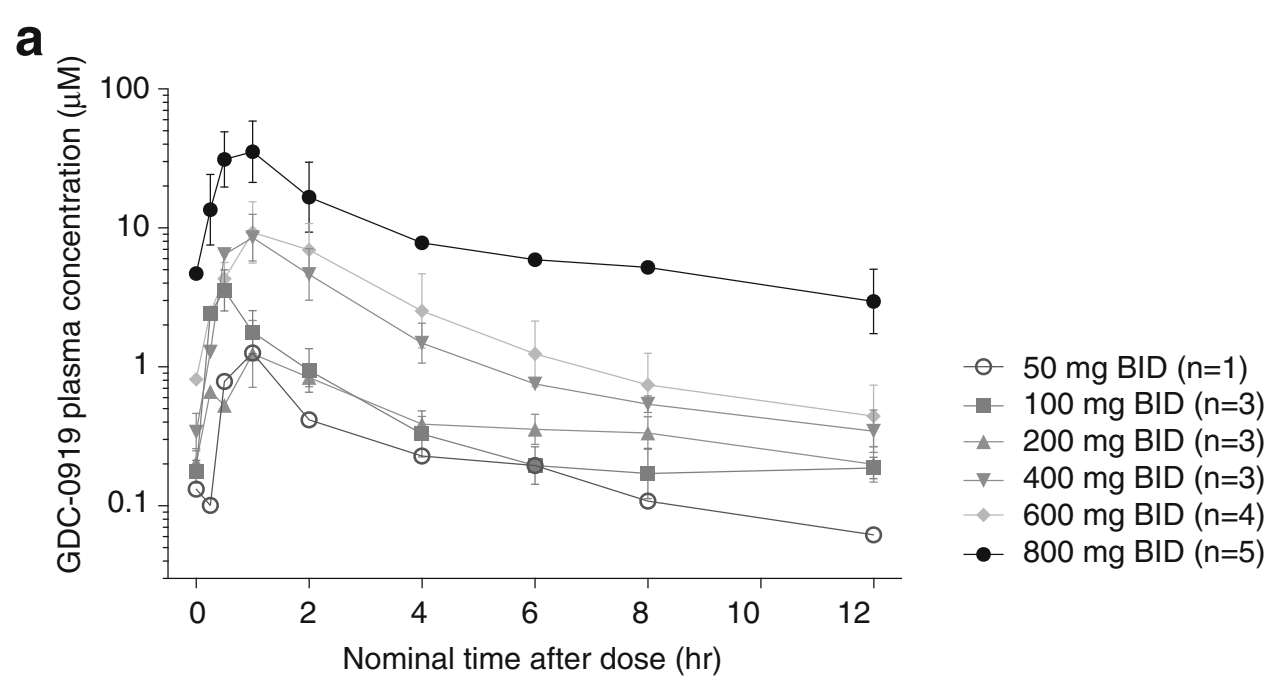

b

\begin{tabular}{|c|c|c|c|c|c|c|}
\hline Parameter & $\begin{array}{c}\text { Navoximod } \\
50 \mathrm{mg} \text { BID } \\
(\mathrm{n}=1)\end{array}$ & $\begin{array}{c}\text { Navoximod } \\
100 \mathrm{mg} \text { BID } \\
(\mathrm{n}=3)\end{array}$ & $\begin{array}{c}\text { Navoximod } \\
200 \mathrm{mg} \text { BID } \\
(\mathrm{n}=3)\end{array}$ & $\begin{array}{c}\text { Navoximod } \\
400 \mathrm{mg} \text { BID } \\
(\mathrm{n}=3)\end{array}$ & $\begin{array}{c}\text { Navoximod } \\
600 \mathrm{mg} \text { BID } \\
(\mathrm{n}=6)^{\mathrm{a}, \mathrm{b}}\end{array}$ & $\begin{array}{c}\text { Navoximod } \\
800 \mathrm{mg} \text { BID } \\
(\mathrm{n}=6)^{\mathrm{c}}\end{array}$ \\
\hline $\begin{array}{l}\mathrm{t} 1 / 2 \text { (hour) } \\
\text { Day } 1, \text { mean } \pm \mathrm{SD}(\% \mathrm{CV})\end{array}$ & 5.75 & $11.2 \pm 7.09(63.5)$ & $10.6 \pm 2.85(26.9)$ & $9.13 \pm 2.53(27.8)$ & $10.7 \pm 5.10(47.6)$ & $17.9 \pm 12.0(67.2)$ \\
\hline $\begin{array}{l}\mathrm{C}_{\max }(\mu \mathrm{M}) \\
\text { Day } 1, \text { mean } \pm \mathrm{SD}(\% \mathrm{CV}) \\
\text { Day } 21, \text { mean } \pm \mathrm{SD}(\% \mathrm{CV})\end{array}$ & $\begin{array}{l}0.743 \\
1.26 \\
\end{array}$ & $\begin{array}{c}3.19 \pm 0.493(15.5) \\
3.71 \pm 1.68(45.2)\end{array}$ & $\begin{array}{c}0.906 \pm 0.409(45.1) \\
1.41 \pm 0.676(47.8)\end{array}$ & $\begin{array}{l}8.61 \pm 4.88(56.7) \\
11.2 \pm 7.29(65.2)\end{array}$ & $\begin{array}{l}15.0 \pm 13.2(87.9) \\
11.1 \pm 5.47(49.4)\end{array}$ & $\begin{array}{l}33.9 \pm 21.0(62.0) \\
45.1 \pm 21.9(48.7)\end{array}$ \\
\hline $\begin{array}{l}\mathrm{C}_{\min }(\mathrm{uM}) \\
\quad \text { Day } 21, \text { mean } \pm \mathrm{SD}(\% \mathrm{CV})\end{array}$ & 0.132 & $0.176 \pm 0.0369(20.9)$ & $0.204 \pm 0.0547(26.8)$ & $0.340 \pm 0.123(36.1)$ & $0.814 \pm 0.983(121)$ & $4.71 \pm 6.0(128)$ \\
\hline $\begin{array}{l}\mathrm{T}_{\max } \text { (hour) } \\
\text { Day } 1, \text { median (range) } \\
\text { Day } 21, \text { median (range) }\end{array}$ & $\begin{array}{l}1 \\
1\end{array}$ & $\begin{array}{c}0.5(0.25-1) \\
0.5(0.25-0.5)\end{array}$ & $\begin{array}{c}1(0.5-1) \\
1(1-2)\end{array}$ & $\begin{array}{l}1(0.5-2) \\
1(0.5-1)\end{array}$ & $\begin{array}{c}1(1-2) \\
1.5(1-2)\end{array}$ & $\begin{array}{c}1(0.5-1) \\
0.5(0.5-1)\end{array}$ \\
\hline $\begin{array}{l}\mathrm{AUC}_{0-12}\left(\mu \mathrm{M}^{*} \text { hour }\right) \\
\text { Day } 1, \text { mean } \pm \mathrm{SD}(\% \mathrm{CV}) \\
\text { Day } 21, \text { mean } \pm \mathrm{SD}(\% \mathrm{CV})\end{array}$ & $\begin{array}{l}1.48 \\
3.08\end{array}$ & $\begin{array}{c}4.6 \pm 2.75(59.7) \\
6.42 \pm 2.88(44.9)\end{array}$ & $\begin{array}{l}2.48 \pm 0.69(27.8) \\
5.49 \pm 1.76(32.1)\end{array}$ & $\begin{array}{l}16.2 \pm 4.76(29.3) \\
21.9 \pm 8.10(37.0)\end{array}$ & $\begin{array}{l}26.9 \pm 19.5(72.5) \\
29.0 \pm 13.9(47.8)\end{array}$ & $\begin{array}{l}54.3 \pm 24.1(44.5) \\
113 \pm 85.9(76.2)\end{array}$ \\
\hline $\begin{array}{l}\mathrm{AUC}_{0-\infty}\left(\mu \mathrm{M}^{*} \text { hour }\right) \\
\text { Day } 1, \text { mean } \pm \mathrm{SD}(\% \mathrm{CV})\end{array}$ & 1.68 & $6.11 \pm 4.16(68.1)$ & $3.89 \pm 0.834(21.4)$ & $18.8 \pm 5.36(28.5)$ & $31.5 \pm 18.9(60.1)$ & $72.0 \pm 35.6(49.4)$ \\
\hline $\begin{array}{l}\text { Accumulation Ratio } \\
\text { Mean } \pm \text { SD }(\% \mathrm{CV})\end{array}$ & 2.09 & $1.63 \pm 0.867(53.3)$ & $2.2 \pm 0.107(4.84)$ & $1.47 \pm 0.852(58.0)$ & $1.26 \pm 0.333(26.3)$ & $1.79 \pm 0.613(34.3)$ \\
\hline
\end{tabular}

a Multiple dose parameters are reported from four subjects

${ }^{b}$ The $600 \mathrm{mg}$ BID cohort includes patients from both the 21/28 and continuous dosing schedules

${ }^{c}$ Multiple dose parameters are reported from five subjects

${ }^{\mathrm{d}}$ Accumulation ratio was calculated using $\mathrm{AUC}_{0-12}$ multiple dose $/ \mathrm{AUC}_{0-12}$ single dose.

$\mathrm{C}_{\max }=$ maximum observed concentration; $\mathrm{T}_{\max }=$ time of maximum observed concentration:

$\mathrm{AUC}_{0-\infty}=$ area under the curve, measured from 0 to $\infty$ hours post-navoximod dose;

$\mathrm{AUC}_{0-12}=$ area under the curve, measured from 0 to 12 hours post-navoximod dose;

$\mathrm{t}_{1 / 2}=$ half-life; $\mathrm{SD}=$ standard deviation, $\mathrm{CV}=$ coefficient of variation.

Fig. 2 a Mean $( \pm$ SD) plasma concentrations of navoximod after multiple twice-daily doses on Cycle 1, Day 21. The 600 mg BID cohort includes patients from both the 21/28 and continuous dosing schedules. $\mathbf{b}$ Single dose and multiple dose pharmacokinetic parameters for navoximod

Navoximod has an in vitro potency against the recombinant purified human IDO enzyme of $28 \mathrm{nM}$ (IC50) with a $\mathrm{K}_{i}$ of $5.8 \mathrm{nM}$. Its potency in cellular assays expressing human IDO is $\mathrm{EC}_{50}$ of $70 \mathrm{nM}$ and an $\mathrm{EC}_{75}$ of $\sim 200 \mathrm{nM}$ and it restores IDO-mediated suppression of $\mathrm{CD}^{+} \mathrm{T}$ cell proliferation in a human MLR assay with an $\mathrm{EC}_{50}$ of $90 \mathrm{nM}$ and an $\mathrm{EC}_{90}$ of $\sim 200 \mathrm{nM}$ [22]. Considering that navoximod has a \%PB of $\sim 50 \%$ (fu $=$ $0.5)$ it could be expected that concentrations that are > $400 \mathrm{nM}$ should achieve $>75 \%$ of IDO-mediated Kyn synthesis inhibition and $>90 \%$ restoration of $\mathrm{T}$ cell proliferation in vivo.

The exposures achieved in this study would thus be expected to maintain trough free drug concentrations above the cellular $\mathrm{EC}_{50}$, at doses of $600 \mathrm{mg}$ or higher (Fig. 2). This is consistent with the observation of more pronounced Kyn suppression in the higher dose cohorts of this study, which indicates that plasma exposures obtained at doses higher than $600 \mathrm{mg}$ may be necessary for optimal systemic modulation of Kyn production in human subjects and for stimulation of $\mathrm{T}$ cell proliferation in vivo.

\section{Discussion}

Navoximod was well-tolerated at doses up to $800 \mathrm{mg}$ BID on a 21/28 day schedule or $600 \mathrm{mg}$ on continuous dosing, with the MTD not reached. The study was closed before completing planned enrollment as a result 


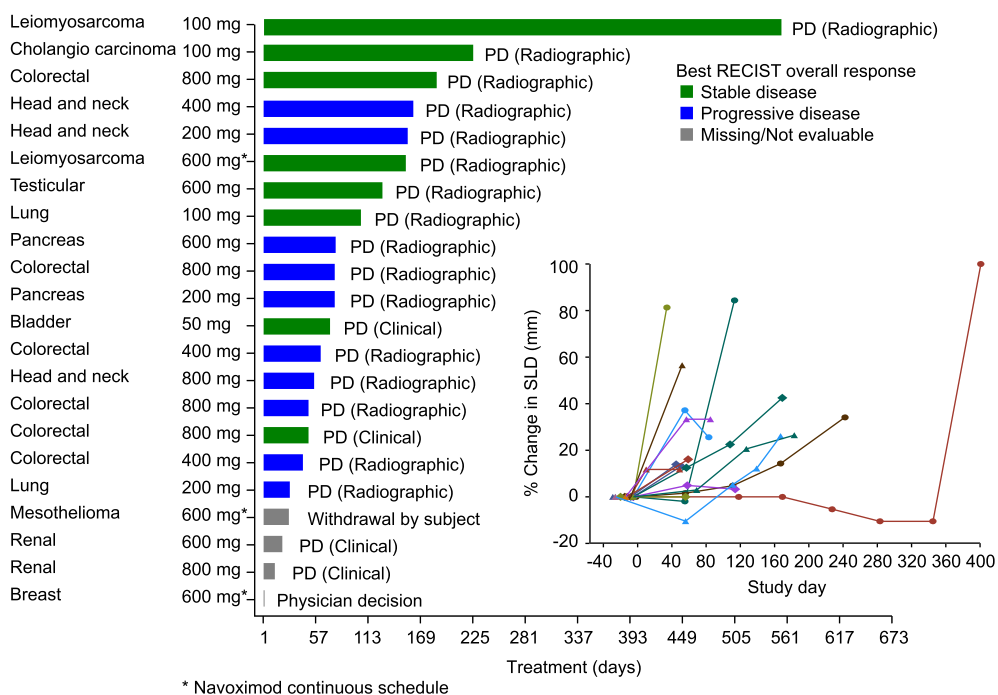

Fig. 3 Time on study treatment (navoximod dose BID), reason for treatment discontinuation, and best response by RECIST/change in sum of longest diameters for individual patients. PD: Progressive disease

of increasing challenges to identifying suitable patients for the study. Navoximod was rapidly absorbed $\left(\mathrm{T}_{\max } \sim\right.$ $1 \mathrm{~h}$ ) and had dose proportional increases in exposure, with a half-life supportive of BID dosing. Best response based on RECIST v1.1 was limited to SD in 8 out of 18 patients with post-baseline tumor assessments. At doses higher than $400 \mathrm{mg}$ BID, plasma Kyn was modulated in a manner consistent with the half-life of the drug and predicted activity based on considerations of potency in in vitro cellular assays and drug free fraction in plasma, with maximal Kyn decreases observed at post-dose timepoints following the $\mathrm{T}_{\max }$ by a few hours, indicating target engagement with peripheral PD effects.

Initially the study completed enrollment of patients at the $21 / 28$ day schedule up to maximum administered dose (MAD) of $800 \mathrm{mg}$ BID. Doses as low as $100 \mathrm{mg}$ BID achieved a trough concentration at $12 \mathrm{~h}$ above the cellular $\mathrm{EC}_{50}$ of $90 \mathrm{nM}$, while doses of $800 \mathrm{mg}$ BID achieved a trough concentration of $4.71 \mu \mathrm{M}$. A 21/28 schedule was initially selected to prevent desensitization to IDO inhibitors after continued IDO inhibition, as is seen in IDO-KO mice [27-29], and to mitigate the

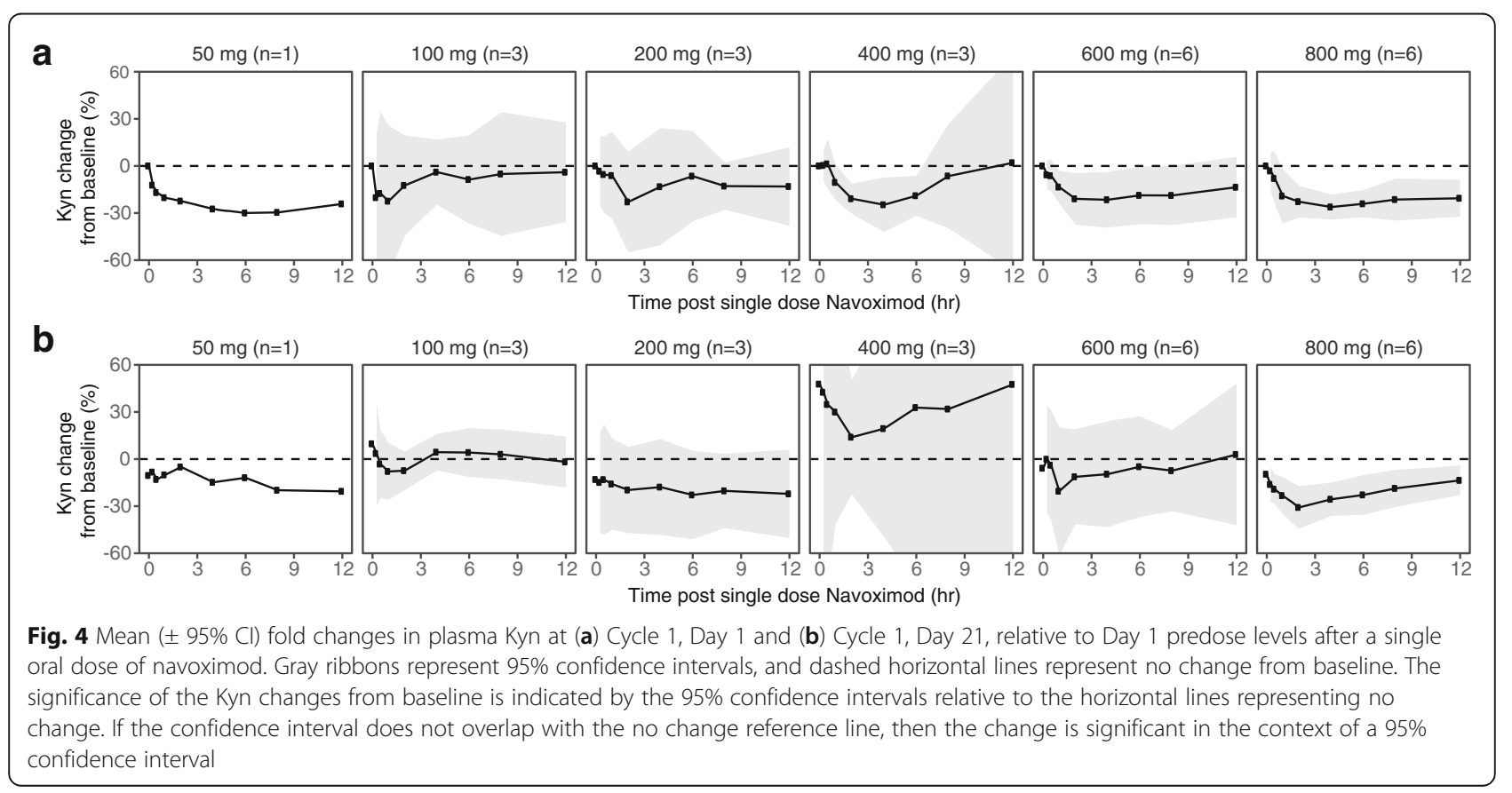


potential for autoinduction of metabolism observed in rats and dogs (Genentech, data on file). PK data from the $21 / 28$ schedule demonstrated an accumulation ratio consistent with the dosing frequency, suggesting that navoximod does not exhibit autoinduction in humans. Therefore, the study was amended to include the evaluation of safety, PK, and peripheral and tumor PD at a 28/28 day schedule at $600 \mathrm{mg}$ BID. Upon limited enrollment of three patients over the course of 1 year the sponsor decided to close the study for limited feasibility of identifying suitable patients for single agent navoximod. Continued safety and PD evaluations were deferred to a parallel Phase Ib study combining continuous navoximod dosing with the anti-PD-L1 agent atezolizumab.

Immune-related AEs have been reported for almost all organ systems after the use of marketed checkpoint inhibitors, including liver toxicity and dermatologic reactions [30]. In this study, none of the AEs were reported as immune-related; however, 1 patient experienced both liver enzyme elevations and rash. A possible relationship between study treatment and elevation of liver enzymes cannot be ruled out and will continue to be monitored in additional studies with navoximod. Rash events were reported in five patients (23\%) overall, which included the terms of rash (three patients, 14\%) and maculo-papular rash (two patients, 9\%). All events were Grade 1-2.

Currently available immune modulators can be effective given as single agents, albeit in a small percentage of patients. The accumulated data targeting the IDO pathway suggests that IDO inhibitors produce minimal antitumor activity when given alone as evidenced by the current study and the Phase I trials of epacadostat and indoximod [17, 31]. Checkpoint inhibitors of PD-1/ PD-L1 show activity as a single agent, though with response rates of less than $20 \%$, cures occurring in less than $5 \%$ of patients in most indications and somewhat increased responsiveness in select indications, such as melanoma, microsatellite instabilityhigh tumors, and Hodgkin's disease [9]. Therefore, combination therapy regimens employing one or more targeted immunotherapy drugs may be required to fully activate the host immune system.

Emerging clinical data from Phase I/II studies suggest the potential for increased benefit from a combination approach with IDO inhibitors. Epacadostat, given in combination with ipilimumab showed the potential for enhanced melanoma patient outcomes compared to ipilimumab monotherapy [32], and epacadostat or indoximod given with pembrolizumab showed promising results in melanoma and solid tumors [18-21, 33]. The preliminary results from the Phase I/II study of daily epacadostat and pembrolizumab in treatment naïve melanoma patients showed an objective response rate of
56\% (15\% complete) [34]. These results have led to the initiation of a Phase III trial of the combination in patients with melanoma. A $61 \%$ response rate was observed in 51 patients with cutaneous melanoma in an early study of indoximod in combination with pembrolizumab [33]. The complete remission rate was $20 \%$ in this study. In a small randomized study of indoximod after sipuleucel vaccine therapy, progression free survival was improved by 6.2 months [35]. The median radiographic progression free survival was 10.3 months compared with 4.1 months in the placebo arm. However, there was no increase in T cell response to PA2024 by ELISPOT or ELISA assay. Additionally, there were no changes in PSA between groups.

In conclusion, navoximod is a novel checkpoint inhibitor with potential immune modulating properties. In this trial we observed liver enzymes elevations and cutaneous toxicities (rash) that should be monitored in further studies that, given evidence of peripheral PD effects via suppression of Kyn as a single agent, warrant further investigation of navoximod in combination with other therapies. A Phase Ib study of navoximod in combination with atezolizumab in patients with solid tumors is currently ongoing (NCT02471846). Preliminary data from dose escalation stage of that study reported a response rate of $9 \%$ in an unselected patient population [36].

\section{Abbreviations \\ AE: Adverse event; AUC: Area under the curve; BID: Twice daily; $C_{\text {max }}$ : Maximum observed concentration; CV: Coefficient of variation; DLT: Dose-limiting Toxicity; ECOG: Eastern Cooperative Oncology group; IDO1: Indoleamine-2,3-dioxygenase 1; IHC: Immunohistochemistry; irRC: Immune-related response criteria; Kyn: Kynurenine; LC/MS-MS: Liquid chromatographic-tandem mass spectrometry; MAD: Maximum administered dose; MTD: Maximum tolerated dose; PD: Pharmacodynamics; \\ PD: Progressive disease; PD-1: Programmed cell death protein 1; PD- \\ L1: Programmed death-ligand 1; PK: Pharmacokinetics; SD: Stable disease; $\mathrm{t}_{1 /}$ 2: Half-life; $T_{\text {max }}$ : Time of maximum observed concentration; Trp: L-tryptophan}

\section{Acknowledgements}

The authors wish many thanks to all of the patients and the investigators who participated in this study. Writing assistance provided by Genentech, Inc.

\section{Funding}

This work was supported by Genentech, Inc.

Availability of data and materials

The data presented in this study is available upon reasonable request to the corresponding authors.

\section{Authors' contributions}

MM, ZH, SNK, EK, and NV conceived of and designed the study. ZH contributed to development of methodology. MM, DM, ZH, SNK, ANK, JEJ, $R D$, and LM acquired study data. EK, RSL, SRJ, KM, SM, BMC, AP, JEJ, and SNK analyzed and interpreted the data. ANK, RD, LM, SRJ, RSL, LS, and KM provided administrative, technical, or material support. ANK, RD, LM, NV, EK, RSL, SRJ, KM, SM, BMC, AP, JEJ, and SNK provided study supervision. The authors take full responsibility for the design of the study, the collection of the data, the analysis and interpretation of the data, the decision to submit the article for publication, and the writing of the article. All authors read and approved the final manuscript. 


\section{Ethics approval and consent to participate}

The protocol was approved by Institutional Review Board at Georgia Cancer Center at Augusta University prior to patient recruitment and was conducted in accordance with the Declaration of Helsinki International Conference on Harmonization E6 Guidelines for Good Clinical Practice. Written informed consent was obtained for all patients prior to performing study-related procedures in accordance with federal and institutional guidelines. The study was registered on ClinicalTrials.gov (NCT02048709).

\section{Competing interests}

AN: None. ZH: None. RS: None. RD: None. LM: Employee of Georgia Cancer Center, no conflicts of interest. NNV: NewLink employee and shareholder. WJR: NewLink employee and shareholder. EK: NewLink employee and shareholder. MM: NewLink employee and shareholder. CL: NewLink employee and shareholder. RL: Employee of Genentech, Inc., shareholder of F. Hoffmann La Roche, Ltd. SRJ: Consultant of Genentech, Inc., shareholder of F. Hoffmann La Roche, Ltd. XL: Employee of Genentech, Inc., shareholder of F. Hoffmann La Roche, Ltd. LS: Employee of Genentech, Inc., shareholder of F. Hoffmann La Roche, Ltd. KM: Employee of Genentech, Inc., shareholder of F. Hoffmann La Roche, Ltd. SM: Employee of Genentech, Inc., shareholder of F. Hoffmann La Roche, Ltd. BM: Employee of Genentech, Inc., shareholder of F. Hoffmann La Roche, Ltd. AP: Employee of Genentech, Inc., shareholder of F. Hoffmann La Roche, Ltd. DHM: NewLink Genetics consultant, research support, shareholder. SNK: Member of NewLink SAB, Preclinical Research Agreement Genentech. JEJ: None.

\section{Publisher's Note}

Springer Nature remains neutral with regard to jurisdictional claims in published maps and institutional affiliations.

\section{Author details}

${ }^{1}$ Georgia Cancer Center at Augusta University, Augusta, GA, USA. ${ }^{2}$ NewLink Genetics, Ames, IA, USA. ${ }^{3}$ Genentech, Inc., South San Francisco, CA, USA. ${ }^{4}$ Present Address: Lombardi Comprehensive Cancer Center, Georgetown University School of Medicine, 3900 Reservoir Rd NW, Washington, DC 20007, USA.

\section{Received: 15 February 2018 Accepted: 7 May 2018}

Published online: 20 June 2018

\section{References}

1. Munn DH, Mellor AL. IDO in the tumor microenvironment: inflammation, counter-regulation, and tolerance. Trends Immunol. 2016;37:193-207.

2. Uyttenhove C, Pilotte L, Théate I, Stroobant V, Colau D, Parmentier N, et al. Evidence for a tumoral immune resistance mechanism based on tryptophan degradation by indoleamine 2,3 dioxygenase. Nat Med. 2003;9:1269-74.

3. Desvignes L, Ernst JD. Interferon gamma responsive non hematopoietic cells regulate the immune response to Mycobacterium tuberculosis. Immunity. 2009;31:974-85.

4. Favre D, Mold J, Hunt PW, Kanwar B, Loke P, Seu L, et al. Tryptophan catabolism by indoleamine 2,3 dioxygenase 1 alters the balance of TH17 to regulatory T cells in HIV disease. Sci Transl Med. 2010;2:32ra6.

5. Polak ME, Borthwick NJ, Gabriel FG, Johnson P, Higgins B, Hurren J, et al. Mechanisms of local immunosuppression in cutaneous melanoma. $\mathrm{Br} J$ Cancer. 2007:96:1879-87.

6. Brody JR, Costantino CL, Berger AC, Sato T, Lisanti MP, Yeo CJ, et al. Expression of indoleamine 2,3 dioxygenase in metastatic malignant melanoma recruits regulatory $T$ cells to avoid immune detection and affects survival. Cell Cycle. 2009:8:1930-4.

7. Witkiewicz A, Williams TK, Cozzitorto J, Durkan B, Showalter SL, Yeo CJ, et al. Expression of indoleamine 2,3 dioxygenase in metastatic pancreatic ductal adenocarcinoma recruits regulatory $T$ cells to avoid immune detection. J Am Coll Surg. 2008;206:849-54.

8. Okamoto A, Nikaido T, Ochiai K, Takakura S, Saito M, Aoki Y, et al. Indoleamine 2,3 dioxygenase serves as a marker of poor prognosis in gene expression profiles of serous ovarian cancer cells. Clin Cancer Res. 2005;11:6030-9.

9. Varga A, Piha-Paul SA, Ott PA, Mehnert JM, Berton-Rigaud D, Morosky A et al. Pembrolizumab in patients with PD-L1-positive (PD-L1+) advanced ovarian cancer: updated analysis of KEYNOTE-028. J Clin Oncol. 2017; 35(suppl):abstr 5513.

10. Curti A, Pandolfi S, Valzasina B, Aluigi M, Isidori A, Ferri E, et al. Modulation of tryptophan catabolism by human leukemic cells results in the conversion of CD25 into CD25+ T regulatory cells. Blood. 2007;109:2871-7.

11. Chamuleau ME, van de Loosdrecht AA, Hess CJ, Janssen JJ, Zevenbergen A Delwel $R$, et al. High INDO (indoleamine 2,3 dioxygenase) mRNA level in blasts of acute myeloid leukemic patients predicts poor clinical outcome. Haematologica. 2008;93:1894-8.

12. Huang A, Fuchs D, Widner B, Glover C, Henderson DC, Allen-Mersh TG. Serum tryptophan decrease correlates with immune activation and impaired quality of life in colorectal cancer. Br J Cancer. 2002;86:1691-6.

13. Brandacher $G$, Perathoner A, Ladurner $R$, Schneeberger S, Obrist $P$ Winkler $C$, et al. Prognostic value of indoleamine 2,3 dioxygenase expression in colorectal cancer: effect on tumor infiltrating T cells. Clin Cancer Res. 2006;12:1144-51.

14. Feder-Mengus C, Wyler S, Hudolin T, Ruszat R, Bubendorf L, Chiarugi A, et al High expression of indoleamine 2,3 dioxygenase gene in prostate cancer. Eur J Cancer. 2008;44:2266-75.

15. Ino K, Yamamoto E, Shibata K, Kajiyama H, Yoshida N, Terauchi M, et al. Inverse correlation between tumoral indoleamine 2,3 dioxygenase expression and tumor infiltrating lymphocytes in endometrial cancer: its association with disease progression and survival. Clin Cancer Res. 2008;14:2310-7.

16. Ino K, Yoshida N, Kajiyama H, Shibata K, Yamamoto E, Kidokoro K, et al. Indoleamine 2,3 dioxygenase is a novel prognostic indicator for endometrial cancer. Br J Cancer. 2006;95:1555-61.

17. Beatty GL, O'Dwyer PJ, Clark J, Shi JG, Bowman KJ, Scherle PA, et al. First-inhuman phase I study of the oral inhibitor of indoleamine 2,3-dioxygenase-1 epacadostat (INCB024360) in patients with advanced solid malignancies. Clin Cancer Res. 2017:23:3269-76.

18. Gangadhar TC, Schneider BJ, Bauer TM, Wasser JS, Spira Al, Patel SP, et al. Efficacy and safety of epacadostat plus pembrolizumab treatment of NSCLC: preliminary phase I/II results of ECHO-202/KEYNOTE-037. J Clin Oncol. 2017; 35(suppl):abstr 9014.

19. Lara P, Bauer TM, Hamid O, Smith DC, Gajewski T, Gangadhar TC, et al. Epacadostat plus pembrolizumab in patients with advanced RCC: preliminary phase I/II results from ECHO-202/KEYNOTE-037. J Clin Oncol. 2017;34(suppl):abstr 4515.

20. Perez RP, Riese MJ, Lewis KD, Saleh MN, Daud A, Berlin J, et al. Epacadostat plus nivolumab in patients with advanced solid tumors: preliminary phase I/ II results of ECHO-204. J Clin Oncol. 2017;35(suppl):abstr 3003.

21. Smith DC, Gajewski T, Hamid O, Wasser JS, Olszanski AJ, Patel SP, et al. Epacadostat plus pembrolizumab in patients with advanced urothelial carcinoma: preliminary phase I/II results of ECHO-202/KEYNOTE-037. J Clin Oncol. 2017;35(suppl):abstr 4503

22. Mautino MR, Link CJ, Vahanian NN, Adams JT, Van Allen C, Sharma MD, et al. Synergistic antitumor effects of combinatorial immune checkpoint inhibition with anti-PD-1/PD-L antibodies and the IDO pathway inhibitors NLG-919 and indoximod in the context of active immunotherapy. Cancer Res. 2014;74(suppl):19.

23. Li M, Bolduc AR, Hoda MN, Gamble DN, Dolisca SB, Bolduc AK, et al. The indoleamine 2,3-dioxygenase pathway controls complement-dependent enhancement of chemo-radiation therapy against murine glioblastoma. J Immunother Cancer. 2014;2:21.

24. Berrong Z, Ahmad S, Abu Eid R, El Andaloussi A, Sen T, Stewart R, et al Immune combinational therapy targeting OX40 and IDO synergistically enhances efficacy of a cancer vaccine. J Immunother Cancer. 2014; 2(suppl 3):P226

25. Spranger S, Koblish HK, Horton B, Scherle PA, Newton R, Gajewski TF. Mechanism of tumor rejection with doublets of CTLA-4, PD-1/PD-L1, or IDO blockade involves restored IL-2 production and proliferation of CD8+ T cells directly within the tumor microenvironment. J Immunother Cancer. 2014;2:3.

26. Spira Al, Hamid O, Bauer TM, Borges VF, Wasser JS, Smith DC, et al. Efficacy/safety of epacadostat plus pembrolizumab in triple-negative breast cancer and ovarian cancer: phase I/II ECHO-202 study. J Clin Oncol. 2017;35(suppl):abstr 1103.

27. Banerjee T, Duhadaway JB, Gaspari P, Sutanto-Ward E, Munn DH, Mellor AL, et al. A key in vivo antitumor mechanism of action of natural product-based brassinins is inhibition of indoleamine 2,3-dioxygenase. Oncogene. 2008;27:2851-7.

28. Hou DY, Muller AJ, Sharma MD, DuHadaway J, Banerjee T, Johnson M, et al. Inhibition of indoleamine 2,3-dioxygenase in dendritic cells by 
stereoisomers of 1-methyl-tryptophan correlates with antitumor responses. Cancer Res. 2007;67:792-801.

29. Muller AJ, DuHadaway JB, Jaller D, Curtis P, Metz R, Prendergast GC. Immunotherapeutic suppression of indoleamine 2,3-dioxygenase and tumor growth with ethyl pyruvate. Cancer Res. 2010;70:1845-53.

30. Collins LK, Chapman MS, Carter JB, Samie FH. Cutaneous adverse effects of the immune checkpoint inhibitors. Curr Probl Cancer. 2016;41:125-8.

31. Soliman HH, Minton SE, Han HS, Ismail-Khan R, Neuger A, Khambati F, et al. A phase I study of indoximod in patients with advanced malignancies. Oncotarget. 2016;7:22928-38.

32. Gibney G, Hamid O, Lutsky J, Oszanski A, Gangadhar T, Gajewski T, et al. Updated results from a phase $1 / 2$ study of epacadostat (INCB024360) in combination with ipilimumab in patients with metastatic melanoma. Eur Cancer. 2015;51:s106-S107.

33. Zakharia Y, McWilliams R, Shaheen M, Shaheen M, Groissman K, Dranick J, et al. Interim analysis of the phase 2 clinical trial of the IDO pathway inhibitor indoximod in combination with pembrolizumab for patients with advanced melanoma. Cancer Res. 2017;13(supplemental):17.

34. Hamid O, Gajewski TF, Frankel AE, Bauer TM, Olszanski AJ, Luke JJ, et al. Epacadostat plus pembrolizumab in patients with advanced melanoma: Phase 1 and 2 efficacy and safety results from ECHO-202/ KEYNOTE-037 Annals of Oncology, Volume 28, Issue suppl_5, 1 September 2017, mdx377.001.

35. Jha GG, Gupta S, Tagawa ST, Koopmeiners JS, Vivek S, Dudek AZ. A phase II randomized, double-blind study of sipuleucel-T followed by IDO pathway inhibitor, indoximod, or placebo in the treatment of patients with metastatic castration resistant prostate cancer (mCRPC). J Clin Oncol. 2017 35(suppl):abstr 3066.

36. Burris HA, Gordon MS, Hellmann MD, LoRusso P. Emens LA, Hodi S, et al. A. phase Ib dose escalation study of combined inhibition of IDO1 (GDC-0919) and PD-L1 (atezolizumab) in patients with locally advanced or metastatic solid tumors. J Clin Oncol. 2017;35(suppl):abstr 105.

\section{Ready to submit your research? Choose BMC and benefit from}

- fast, convenient online submission

- thorough peer review by experienced researchers in your field

- rapid publication on acceptance

- support for research data, including large and complex data types

- gold Open Access which fosters wider collaboration and increased citations

- maximum visibility for your research: over $100 \mathrm{M}$ website views per year

At BMC, research is always in progress.

Learn more biomedcentral.com/submissions 